\title{
Primary Cutaneous Apocrine Carcinoma of Sweat Glands: A Rare Case Report
}

\author{
T. Vasilakaki \\ E. Skafida \\ E. Moustou \\ X. Grammatoglou \\ E. Arkoumani \\ K. Koulia \\ A. Tsavari \\ E. Delliou \\ Department of Pathology, 'Tzaneion' General Hospital, Piraeus, Greece
}

\section{Key Words}

Apocrine gland carcinoma $\cdot$ Sweat gland carcinoma $\cdot$ Axillary mass

\begin{abstract}
Cutaneous apocrine gland carcinoma, a subtype of sweat gland carcinoma, is a very rare malignancy, and only few cases have been reported in the literature. Many of these carcinomas are indolent and slowly developing, but some are rapidly progressive. The treatment of choice is wide local excision with clear margins, with or without lymph node dissection. We report a case of a 67-year-old man who came to our hospital with an ulcerated nodule in the right axilla measuring $1 \times 0.8 \mathrm{~cm}$. Histological evaluation showed features of an apocrine gland carcinoma arising in an area of high apocrine gland density.
\end{abstract}

\section{Introduction}

Primary cutaneous apocrine gland carcinoma, a subtype of sweat gland carcinoma, is an extremely rare malignant neoplasm [1-3]. Most of these neoplasms involve the axilla, but lesions can also occur elsewhere on the skin. Most often, they are indolent and slowly developing, but some are rapidly progressive and extremely aggressive [1, 4-6]. In fact, some patients have died from widespread metastases. The treatment of choice is wide local excision with clear margins, with or without lymph node dissection $[1,3,5,7]$.

\section{Case Report}

A 67-year-old man presented to our hospital with an ulcerated nodule in the right axilla measuring $1 \times 0.8 \mathrm{~cm}$. The nodule had been present for more than 3 years, but only grew in size over the past 6 months. Bilateral breast examination, skin examination and complete lymph node survey were unremarkable. Ultrasound examination and a mammogram revealed no significant lesions in either 
breast, consistent with the physical examination. There was no family history of malignancy. The nodule was excised and the specimen submitted for histopathological examination.

Microscopic examination revealed a well-to-moderately differentiated adenocarcinoma which contained ductal and glandular structures with obvious apocrine features. Some of the glandular lumens showed decapitation secretion. In addition, the cytoplasm of the tumour cells contained PAS-positive diastase-resistant granules without iron-staining granules. The tumour tissue invaded the papillary and reticular dermis and ulcerated the epidermis without extension to the subcutaneous tissue (fig. 1, fig. 2). Many apocrine glands were present near the carcinoma. The immunohistochemical study showed that the tumour cells were positive for Ker7, EMA and E-cadherin and negative for CEA, S100p and PSA. No oestrogen or progesterone receptors were detected, making the diagnosis of male breast cancer metastatic to the axilla unlikely ( $\underline{\mathbf{f i g} .3}$, $\underline{\text { fig. }} \mathbf{4}$ ).

Based on the above characteristic morphologic and immunohistochemical findings, the diagnosis of primary apocrine carcinoma was made. Two years later, the patient showed no evidence of metastasis.

\section{Discussion}

Cutaneous apocrine gland carcinoma, a subtype of sweat gland carcinoma, is a very rare malignant neoplasm arising in areas of high apocrine sweat gland density. To date, only few cases (about 50 cases) have been reported in the literature [1]. The first report was published in 1944 [8].

These lesions occur primarily in the axilla, but can also occur elsewhere on the skin $[1-3,9]$. The disease is diagnosed in the fifth to seventh decade of life. Apocrine adenocarcinoma usually develops de novo but has also been observed to arise in association with other benign tumours such as apocrine adenoma and apocrine hyperplasia $[10,11]$. Most of the neoplasms are relatively indolent and slowly developing over months to years, but some are rapidly progressive and extremely aggressive. They mostly present as nodules or masses $2-3 \mathrm{~cm}$ in size, without any additional symptoms $[1,3,5,6]$. One third of the patients have regional lymph node involvement at diagnosis. Also, some patients have died from metastases to the lungs, liver, bone, brain and kidney [1, 3, 5].

The histologic picture likes as an adenocarcinoma that may be well, moderate or poorly differentiated $[1,3,9]$. The adenocarcinoma contains ductal or glandular structures with apocrine features. The cytoplasm of the tumour cells contains PASpositive, diastase-resistant granules and often iron-positive granules $[1,7,9,12]$.

The differential diagnosis of apocrine gland carcinoma from metastatic mammary adenocarcinoma is not possible on morphological grounds, and immunohistochemistry, except for a few cases, does not allow distinction between them. Malignant sweat gland tumours are often positive for oestrogen and progesterone receptors, and these markers are therefore of limited usage in differential diagnosis [1, 3, 9]. Features that favour the diagnosis of a primary apocrine gland carcinoma are the presence of neoplastic glands high in the dermis, apocrine glands near the tumour and intracytoplasmic granules of iron [9]. The treatment of choice is wide local excision with clear margins, with or without regional lymph node dissection. Postoperative radiotherapy and chemotherapy in patients with moderately or poorly differentiated tumours have been used as adjunctive treatments but have shown little benefit on mortality $[1,3,5,13,14]$. There is a high incidence of local recurrence $(28 \%$ in one 
report), and prophylactic nodal dissection does not reduce the incidence of local recurrence [15].

Primary apocrine carcinoma of sweat glands is a very rare tumour, and there are no guidelines for the treatment of recurrent or metastatic disease. Therefore, patients with metastatic progression have a very poor prognosis.



Fig. 1. Apocrine carcinoma. HE. $\times 40$.



Fig. 2. Apocrine carcinoma. HE. $\times 200$. 


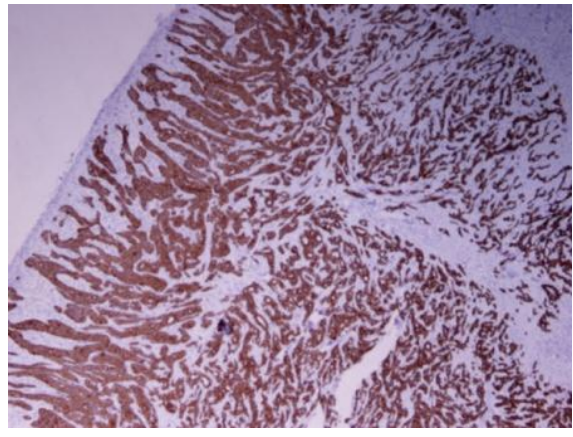

Fig. 3. Apocrine carcinoma. KER 7. $\times 40$.

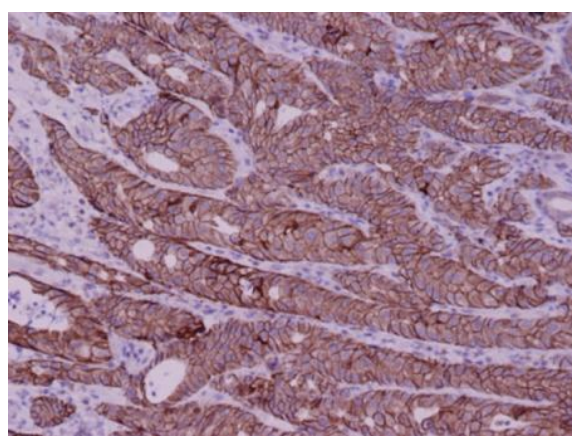

Fig. 4. Apocrine carcinoma. E-cadherin. $\times 200$.

\section{References}

1 Pucevich B, Catinchi-Jaime S, Ho J, Jukic MD: Invasive primary ductal apocrine adenocarcinoma of axilla: a case report with immunohistochemical profiling and a review of literature. Dermatol Online J 2008;14:5.

-2 Robson A, Lasar AJ, Ben Nagi J, Hanby A, Grayson W, Feinmesser M, Granter SR, Seed P, Warneke CL, Mckee PH, Calonje E: Primary cutaneous apocrine carcinoma: a clinico-pathologic analysis of 24 cases. Am J Surg Pathol 2009;33:155-157.

-3 Roy SH, Shati QN, Rose GM: Locally recurrent and metastatic apocrine gland carcinoma in an elderly man. Nat Clin Pract Oncol 2007;4:56-59.

4 Paties C, Taccagni GL, Papotti M: Apocrine carcinoma of the skin: a clinicopathologic immunohistochemical and ultrastructural study. Cancer 1993;71:375-381.

-5 Chamberlain RS, Huber K, White JC, Travaglino-Parda R: Apocrine gland carcinoma of the axilla: review of the literature and recommendations for treatments. Am J Clin Oncol 1999;22:131-135.

-6 Hayes MM, Matisic JP, Weir L: Apocrine carcinoma of the lip: a case report including immunohistochemical and ultrastructural study, discussion of differential diagnosis and review of the literature. Oral Surg Oral Med Oral Pathol Oral Radiol Endod 1996;82:193-199.

-7 Chintamani, Sharma R, Badran R, Singhal V, Saxena S, Bansal A: Metastatic sweat gland adenocarcinoma: a clinico-pathological dilemma. World J Surg Oncol 2003;1:13.

8 Horn RC: Malignant papillary cystadenoma of sweat glands with metastases to the regional lymph nodes. Surgery 1944;16:348-355.

9 Elder DE, Elenitsas R, Johnson BL Jr, Murphy GF, Xu G: Carcinoma of apocrine glands; in: Lever's Histopathology of the Skin, ed 10. Philadelphia, Lippincott Williams \& Wilkins, 2008, pp 895-896. 
10 Nishikawa Y, Tokusashi Y, Saito Y, Ogawa K, Miyokawa N, Katagiri M: A case of apocrine adenocarcinoma associated with hamartomatous apocrine gland hyperplasia of both axillae. Am J Surg Pathol 1994;18:832-836.

11 Miyamoto T, Hayari Y, Inone S, Watanabe T, Yoshino T: Axillary apocrine carcinoma with benign apocrine tumours: a case report involving a pathological and immunohistochemical study and review of the literature. J Clin Pathol 2005;58:757-761.

12 Zehr KJ, Rubin M, Ratner L: Apocrine adenocarcinoma presenting as a large ulcerated axillary mass. Dermatol Surg 1997;23:585.

-13 Kuno Y, Numata T, Kanzaki T: Adenocarcinoma with signet ring cells of the axilla showing apocrine features: a case report. Am J Dermatopathol 1999;21:37-41.

14 Kycler W, Korski K, Laski P, et al: Metastatic apocrine adenocarcinoma of the axillary area. Reports of Practical Oncology and Radiotherapy 2006;11:299-302.

15 Cooper PH: Carcinomas of sweat glands. Pathol Annu 1987;22:83-124 